Bond University

Research Repository

\title{
Tapering practices of elite CrossFit athletes
}

Pritchard, Hayden J.; Keogh, Justin W.; Winwood, Paul W.

Published in:

International Journal of Sports Science and Coaching

DOI:

$10.1177 / 1747954120934924$

Licence:

Other

Link to output in Bond University research repository.

Recommended citation(APA):

Pritchard, H. J., Keogh, J. W., \& Winwood, P. W. (2020). Tapering practices of elite CrossFit athletes.

International Journal of Sports Science and Coaching, 15(5-6), 753-761.

https://doi.org/10.1177/1747954120934924

\section{General rights}

Copyright and moral rights for the publications made accessible in the public portal are retained by the authors and/or other copyright owners and it is a condition of accessing publications that users recognise and abide by the legal requirements associated with these rights.

For more information, or if you believe that this document breaches copyright, please contact the Bond University research repository coordinator. 


\section{Tapering practices of elite CrossFit athletes}

Tapering practices of CrossFit athletes

Hayden J Pritchard, Justin W Keogh \& Paul W Winwood

Dr Hayden J Pritchard - Senior Lecturer in the Department of Exercise \& Wellness, Faculty of Health Sciences at the Universal College of Learning, Palmerston North, New Zealand.

ORCiD: https://orcid.org/0000-0001-5075-6410

A/Prof. Justin W Keogh - Associate Professor in the: ${ }^{1}$ Faculty of Health Sciences and Medicine at Bond University, Queensland, Australia; ${ }^{2}$ Sports Performance Research Institute New Zealand, Auckland University of Technology, Auckland, New Zealand; ${ }^{3}$ Cluster for Health Improvement, Faculty of Science, Health, Education and Engineering, University of the Sunshine Coast, Queensland, Australia and, ${ }^{4}$ Kasturba Medical College, Mangalore, Manipal Academy of Higher Education, Manipal, Karnataka, India ORDiD: https://orcid.org/0000-0001-9851-1068

Dr Paul W Winwood - Senior Lecturer in the ${ }^{1}$ Department of Sport and Fitness, Faculty of Health, Education and Environment at the Toi Ohomai Institute of Technology, Tauranga, New Zealand; and, ${ }^{2}$ Sports Performance Research Institute New Zealand, Auckland University of Technology, Auckland, New Zealand.

ORCiD: https://orcid.org/0000-0003-0021-7739

Corresponding Author:

Hayden Pritchard

UCOL Exercise \& Sport Science

Corner King \& Princess Streets

Palmerston North 4442

New Zealand

Phone: (06) 9527001 ext: 70657

Email: h.pritchard@ucol.ac.nz 


\section{Abstract}

This is the first study to document the training and tapering practices of elite CrossFit athletes. Seventy-two CrossFit athletes (39 females, 33 males) (mean \pm SD; $26.5 \pm 3.6 y, 167.1 \pm 9.5 \mathrm{~cm}$, $74.5 \pm 12.7 \mathrm{~kg}, 12.8 \pm 6.5 y$ general training, $5.4 \pm 1.7$ y CrossFit training) who competed at the "Regionals" level or higher in the 2018 CrossFit Games season completed a self-reported 5page online survey. Almost all athletes (98.6\%) tapered before important competitions. Taper length was $5.4 \pm 2.7$ days, with the step and linear tapering styles being most commonly utilised. Strength training volume peaked $5.1 \pm 4.6$ weeks before competition, whereas conditioning training volume peaked $4.0 \pm 4.4$ weeks before competition. Strength training intensity peaked $3.1 \pm 2.4$ weeks before competition, whereas conditioning training intensity peaked $2.8 \pm 2.2$ weeks before competition. Almost all athletes $(90.0 \%)$ reduced training duration during tapering, but changes to frequency and intensity were mixed. Training volume decreased by $41.2 \pm 15.5 \%$ during the taper, all training ceased $2.0 \pm 1.1$ days before competition. Tapering was performed to achieve peak performance, recover (physically and psychologically), and reduce feelings of fatigue. Poor results from tapering were experienced when athletes tapered for too long or insufficiently. This observational data may be valuable for coaches and athletes engaged in CrossFit as well as other sports with concurrent training and competition demands.

Key words: concurrent training, peaking, periodisation, sport 


\section{Introduction}

Crossfit is a training methodology, and competitive sport, that has become popular around the globe ${ }^{1}$. The sport of CrossFit involves athletes competing in a range of events that encompass a plethora of fitness domains. Athletes may compete in events ranging from pure strength events (e.g. 1RM barbell movements) to endurance events (e.g. a marathon row), with a vast array of technical skills required; from swimming to gymnastics. Sometimes events are unknown to athletes until moments before they compete. Prior to 2019, qualification for the CrossFit Games (i.e. the World Championships) was a multi-stage process that began with an online competition (the "Open"), from which the top athletes from each region of the world would compete at various regional events (the "Regionals") to qualify for the CrossFit Games $^{2}$. While CrossFit is now practiced in more than 140 countries $^{3}$, how these athletes train and peak for performance at major events has yet to be investigated. Such information may be useful for coaches and athletes to improve their training and tapering practices and competition performances.

The sport of CrossFit has a broad range of competition demands, so athletes will need to perform a mixture of both aerobic and strength training to prepare for competition. Thus, CrossFit is a sport that requires concurrent training - training for both short duration, maximal effort activities, as well as sustained endurance activities ${ }^{4}$. Athletes who perform training to enhance these contrasting physiological demands have been shown to experience the interference effect, whereby aerobic training can cause attenuated adaptations to strength training ${ }^{4}$. This interference effect can negatively influence adaptations in general training and could influence tapering requirements when peaking for competition, given that in one 
competition a CrossFit athlete could be expected to compete in a solely endurance event, followed by a pure strength event, as well as mixed modality events. Thus, these contrasting competitive demands could influence the tapering strategies CrossFit athletes choose to implement in order to maximise performance, and these may differ from other sports.

Tapering is the final stage of an athlete's preparation for competition. It aims to allow athletes to recover from the fatigue of training, so that performance can be maximised at a specific time point ${ }^{5}$. While there has been considerable research into tapering for endurance sports ${ }^{6}$, and more recently investigations into strength sports ${ }^{7}$, there has been little investigations into how best to taper for individual sports like CrossFit that involve considerable concurrent training and only a few major competitions each year ${ }^{8,9}$. It has been suggested that experienced endurance athletes should reduce training volume by $>50 \%$, for at least one week (up to one month) before major competitions, while intensity should be maintained or slightly increased ${ }^{6}$. Similar recommendations were made, by the same group, for experienced anaerobic athletes ${ }^{6}$. Furthermore, Pritchard et $a .^{7}$ recommended strength athletes to considerably reduce training volume by $>50 \%$, while making smaller changes (if any) to training intensity. Reductions in training volume during tapering have also been able to elicit performance improvements in combat ${ }^{8,9}$ and team sport athletes ${ }^{10,11}$. Judo athletes who reduced training load (i.e. session RPE $x$ duration) by $\approx 65 \%$ during a two-week taper after two weeks of intensified training improved performance in anaerobic endurance and power tests $^{8}$, while Taekwondo athletes showed greater effect size performance improvements across a range of physical tasks when reducing training load by $50 \%$ after 10 -weeks of overload training ${ }^{9}$. Soccer players increased the number of high-intensity runs, along with other in-match physical activities, following in-season tapers that decreased training load 
by $22.5 \%{ }^{11}$. Such sports have similarities to CrossFit, with high demands on both aerobic and anaerobic energy production, as well as high technical demands. When athletes have been training with higher training loads (i.e. overreaching) prior to a taper, larger reductions in training volume, and/or a longer taper period, may be recommended ${ }^{6,12}$. As CrossFit athletes are purported to utilise high training loads in order to develop the high levels of aerobic and anaerobic fitness characteristics they require, they may be at relatively high risk of overreaching, overtraining and/or injury. It would be expected that effective tapering practices for the sport would be characterised by reductions in training volume, with intensity maintained in order that these athletes feel fully recovered by competition day and still able to maintain their anaerobic and aerobic capacities as well as the technical skills required for their events.

However, as there is no scientific literature investigating the training and tapering practices of CrossFit athletes, this study aimed to investigate the training and tapering practices employed by elite CrossFit athletes. Typical training characteristics data were collected to give insight into CrossFit athletes' pre-taper approaches to place the tapering data in context. It was hypothesised that elite CrossFit athletes would perform tapers that focus on reductions in training volume while intensity is maintained. 


\section{Materials and Methods}

\section{Experimental Overview}

A comprehensive CrossFit tapering practices survey was distributed directly to eligible athletes online, this survey aimed to determine how elite CrossFit athletes taper for their major CrossFit competitions. The survey was adapted from an online survey previously used with Strongman athletes ${ }^{13}$, which was shown to produce reliable responses ${ }^{14}$.

\section{Participant recruitment}

Elite CrossFit athletes were recruited through social media platforms through direct messaging. Specifically, athletes from the 2018 CrossFit Games season who had competed at the CrossFit Regionals level of competition (as an individual), or higher, were identified as meeting the inclusion criteria and sent direct messages via the social media platform of Instagram. Where an individual could not be located on Instagram, the social media platform of Facebook was used. Some individuals could not be located on either platform and as such they were not sent a direct message. Of the 712 potential athletes identified, 703 were sent messages inviting them to participate.

The message sent to athletes briefly described the research objectives and invited them to participate via a link to the survey. Surveygizmo.com was the platform used for the electronic survey, which was in the English language. On the first page of the survey, an information sheet was provided with the objectives and purpose of the study. Participants were asked to indicate their consent by completing the survey. Participants were able to exit the survey at any time and resume the survey at another time. To ensure accuracy in the answers provided, 
participants were encouraged to refer to their training diaries and/or complete the survey alongside their coach. The methods and procedures used in this study were approved by the Toi Ohomai Research Committee (TRC 2018.003)

\section{Participants}

The survey was link was sent to 703 CrossFit athletes who met the inclusion criteria. Of the 703 athletes sent the message, 355 opened the message (50.5\%). Seventy-two athletes who opened the message (39 females, 33 males) completed the survey, representing $20.3 \%$ of those who opened the message. In order to meet the criteria for completing the survey, participants had to complete the first three sections of the survey on demographics and background, training practices, and tapering.

\section{Research Instrument}

Crossfit athletes complete a self-reported 5-page, 39-item, retrospective The Tapering Practices of CrossFit ${ }^{\circledast}$ Athletes survey created for this study based on a previous study used with strongman athletes ${ }^{13}$. The original survey was pilot tested with research associates from a number of universities, and several 2018 CrossFit Regional Level Team athletes to ensure its user-friendliness with the target population. Following pilot testing, the survey was refined prior to invites being sent.

The survey consisted of five main areas of inquiry: 1) demographics and background information, 2) training practices, 3) tapering, 4) general tapering practices, and, 5) specific tapering practices. The demographics and background section included questions on sex, age, height, body mass, country of origin, training experience (general and CrossFit specific), 
CrossFit competition experience, 2018 CrossFit competition level, and coaching. The training practices section included questions on training frequency, training types, length of sessions, training modality breakdown, and changes to training during the competitive season. The tapering section asked athletes whether they have ever used a taper, and if not, the reasons why not. The general tapering practices section included questions on why a taper is used, if a taper is always used, and the type of taper used. The specific tapering practices section included questions on the length of the taper, when volume and intensity peaks in relation to a competition (for both strength and conditioning components), how volume, intensity, frequency and training modalities used are altered during a taper, when training ceased for specific exercises (and all training), and an opportunity to describe other factors involved in or influencing - the taper. A variety of both open and closed questions were used throughout the survey.

To understand how athletes train for the various physiological demands of the sport, training types were broadly categorised as strength training (performing sets and reps with load on resistance exercises), aerobic conditioning (long duration steady state conditioning at submaximal intensities), and anaerobic conditioning (repeated, high intensity, short duration exercise). Furthermore, to better understand the modalities included in training, training modalities were defined as powerlifting and associated lifts (squat, deadlift, press/push press and bench press), weightlifting and weightlifting derivatives (snatch, clean, jerk, clean and jerk), gymnastics (pull ups, toes to bar, knees to elbows, lunges, muscle ups, burpees, dips, gluteus-hamstring developer sit ups, push-ups, rope climbs, handstand push-ups and pistols), mono-structural (rowing, cycling, running and sprints), and other (kettlebell swings, thrusters, 
Turkish get-ups, box jumps, double unders, etc.). These definitions were adapted from previous descriptions of CrossFit training ${ }^{15,16}$.

Within the survey, tapering was defined as "a reduction in training load (volume and/or intensity of training) over a period of time prior to a CrossFit ${ }^{\circledR}$ event" $^{\prime \prime}$ specifically in relation to the competition representing the highest priority for a given athlete. Classifications of tapering (step, linear, exponential with slow or fast decay) were based upon previously described definitions ${ }^{17}$. These were defined within the survey as: a step taper involves a complete and immediate decrease in training volume (e.g. decreasing volume by $50 \%$ on the first day of the taper and maintaining this throughout the duration of the taper), a linear taper involves a decrease in volume in a progressive linear fashion (i.e. a decrease of $5 \%$ of initial values every workout), an exponential taper with a slow decay (e.g. a slow exponential decay with a half-life of 6 days means that every 6 days training volume would be decreased by half), and an exponential taper with a fast decay (e.g. a fast exponential decay with a half-life of 3 days means that every 3 days training volume would be decreased by half).

\section{Statistical Analyses}

For all numerical participant, training and taper training characteristics data, means and standard deviations were calculated. For all categorical and ordinal data, the absolute number of responses and percentage of responses were reported. These data were reported for all participants, as well as for males and females. 
Two-tailed $t$-tests were used to determine any statistically significant differences $(P \leq 0.05)$ in any of the demographic or training data of elite CrossFit athletes as a function of sex. Where data was not normally distributed, the Mann Whitney non-parametric test was used. Differences among male and female participants regarding coaching, tapering characteristics and practices were analysed with a Chi-square test. A one way ANOVA with Games Howell post hoc tests were used to determine if statistical differences existed among weightlifting and powerlifting movements for loads used and when last performed prior to competition. SPSS 25.0 for Windows (SPSS Inc., Chicago, IL, USA) was used for all statistical analyses.

Responses to open ended questions were content analysed, as described previously with similar survey methods ${ }^{13}$. For each relevant open-ended question, higher order themes were developed and presented, along with the number of responses representing that theme, and examples of raw data representing such a response. Microsoft Excel (Microsoft, Seattle, WA) was used when manually analysing response counts for higher order themes. 


\section{Results}

Seventy-two participants completed the survey. Table 1 contains descriptive information of all participants, and for each sex. Participants had been training for $12.8 \pm 6.5$ years, of which $5.4 \pm 1.7$ years was specific CrossFit training, and $4.4 \pm 1.7$ years of competition within the sport. There were no significant differences between male and female athletes for all the outcomes presented in Table 1, with the exception that males were taller and heavier than their female peers.

- Insert Table 1 about here -

Participants from 19 countries responded to the survey. The country of origin of participant's were: United States of America 37, Canada 6, Australia 5, Brazil 3, Mexico 3, France 2, New Zealand 2, Portugal 2, Switzerland 2, Argentina 1, Belgium 1, Germany 1, Iceland 1, Latvia 1, South Korea 1, Spain 1, Thailand 1, United Arab Emirates 1, and the United Kingdom 1. In 2018, the highest level of competition for 7 of these athletes was the CrossFit Games, the remaining 65 had competed at the CrossFit Regionals.

Table 2 provides a summary of the higher order themes, responses and representative quotes for how training focus changed during the taper for different competitions. These higher order themes demonstrated some changes in training emphasis occurred across different phases, but also highlighted considerable within-athlete differences. 
Almost all athletes (98.6\%) tapered before important competitions, with the step and linear tapering styles being the most commonly types utilised. The majority $(75.0 \%)$ of athletes had a coach (see Table 3). Furthermore, physical recovery was the most common theme associated with why athletes taper before competition (see Table 4). Almost all athletes $(90.0 \%)$ reduced training duration during the taper, and large reductions occurred in training volume (by $\mathbf{4 1 . 2} \pm \mathbf{1 5 . 5 \% )}$. However, changes to frequency and intensity were mixed (see Table 5). When tapering wasn't effective, it was usually because athletes tapered for too long prior to the competition (see Table 6).

- Insert Table 3 about here -

- Insert Table 4 about here -

- Insert Table 5 about here-

- Insert Table 6 about here -

The types of training, by percentage of total training time, undertaken during the taper showed some changes compared to regular training (see Figure 1). While different resistance training movements were last performed at various stages before competition (see Table 7); with significant differences found with the final Clean \& Jerk, Back Squat and Deadlift sessions being performed further from competition than the Snatch. A complete overview of the 
general tapering timeline is shown in Figure 2, clearly demonstrating that training volume for both strength and conditioning aspects peaked many weeks out from competition.

- Insert Figure 1 about here -

- Insert Table 7 about here -

- Insert Figure 2 about here - 


\section{Discussion}

This is the first study to document the training and tapering practices of elite CrossFit athletes. Elite CrossFit athletes trained for $5.5 \pm 0.6$ days per week for $120.7 \pm 36.7$ minutes per session, training a variety of energy systems within these sessions. Training approaches differed before the various levels of competition. The majority of athletes $(75.0 \%)$ had a coach. Tapering was utilised by $98.6 \%$ of athletes, with the majority using step (42.4\%) or linear (30.3\%) tapers. During the taper, training duration was decreased by almost all athletes (90.0\%), along with large reductions in overall training volume (by $\mathbf{4 1 . 2} \pm 15.5 \%)$. However, changes in intensity and frequency were variable. Tapers were performed to enhance physical recovery, as well as to achieve peak performance and psychological readiness. When tapering was unsuccessful, it was usually because athletes tapered for too long.

Tapering is focused around reducing the training stress in order to reduce fatigue and thus maximise performance ${ }^{18}$. During a taper, training stress can be reduced through manipulating training intensity and/or volume. Reductions in training volume should be a major focus of a taper, while maintaining higher training intensity a potentially beneficial strategy, across a variety of sports ${ }^{7,18}$. Large reductions in training volume were undertaken by elite CrossFit athletes, volume was reduced by $41.2 \pm 15.5 \%$ which was similar to Strongman competitors $(45.5 \pm 12.9 \%)^{13}$, but less than New Zealand $(58.9 \pm 8.4 \%)^{19}$ and Croatian Powerlifters $(50.5$ $\pm 11.7 \%)^{20}$. Researchers have also demonstrated that large reductions in training load may be beneficial after overload training in Taekwondo $(50 \%)^{9}$, Rugby League $(\approx 55 \%)^{10}$, and Judo $(\approx 55 \%)^{8}$ athletes. Thus, the reduction in training volume reported by CrossFit athletes in the current study meets the recommendations of $41-60 \%$ volume reduction found to be most 
effective by Bosquet et al. ${ }^{21}$ in competitive athletes across a variety of sports. However, smaller reductions in training load have been demonstrated to be effective at improving performance, albeit during in-season training, in Soccer $(\approx 22.5 \%)^{11}$. Thus, elite CrossFit athletes significantly reduce training volume during the taper, in a similar manner to other strength athletes, but it could be argued slightly larger reductions could be beneficial given the demands of the sport.

Elite CrossFit athletes were found to begin tapering later than Powerlifters, and perform their final training session closer to competition than other strength athlete ${ }^{13,19,20}$. Pritchard et al. ${ }^{19}$ found that elite New Zealand Powerlifters began tapering $16.8 \pm 6.3$ days out from an event, similarly Grgic et al. ${ }^{20}$ found that Croatian Powerlifters began tapering $18 \pm 8$ days out. However, the present study found CrossFit athletes tapered for only $5.4 \pm 2.7$ days, which was more similar to Strongman athletes who tapered for $8.6 \pm 5.0$ days ${ }^{13}$. The final heavy $(>85 \%$ 1RM) resistance training session was performed $5.8 \pm 3.2$ days out, which is consistent with what has been found previously for Powerlifters and Strongman competitors which, depending on the strength exercise, was from 4-11 days out ${ }^{13}, 19,20$. However, CrossFit athletes perform their final training session closer to competition ( $2.0 \pm 1.1$ days) compared to both New Zealand ( $3.7 \pm 1.5$ days) and Croatian ( $3 \pm 1$ days) Powerlifters, and Strongman competitors ( $3.9 \pm 1.8$ days). Although the elite CrossFit athletes completed the final training session closer to competition than Powerlifters and Strongman competitors, it is still within the potentially beneficial range of training cessation for strength expression based on previous studies $^{22,23}$. 
There was some inter-athlete variation in how the elite Crossfit athletes altered their training intensity during the taper, with $48 \%, 32 \%$ and $20 \%$ reducing, maintaining or increasing their training intensity, respectively. This means a slight majority (52\%) of athletes were following the recommendations from literature ${ }^{6,7,18}$. Both Pritchard et al. ${ }^{19}$ and Grgic et al. ${ }^{20}$ didn't provide quantitative data for athletes' changes in intensity, but it appears the majority of the Powerlifters in those studies maintained or increased intensity during the taper. In contrast, the majority of Strongman competitors were found to decrease intensity during the taper (55\% of athletes surveyed). While Spilsbury et al. ${ }^{24}$ reported that middle distance, long distance and marathon runners' peak interval training intensities were equal to, or greater than, race intensities during the taper - few studies have reported the practices of elite athletes in endurance sports. In team sports, Fessi et al. ${ }^{11}$ demonstrated maintaining intensity while reducing training load during in-season tapering was associated with an increase in physical activities, such as high speed running, during matches in professional Soccer players. While nearly half $(48 \%)$ of athletes in the current study stated they decreased training intensity, it is possible that the varied demands of training for the sport made an overall change in intensity difficult to quantify. For example, some athletes described decreases in strength training loads prior to certain events, but it is possible metabolic conditioning intensity may have been maintained or increased. Thus, a limitation within this study is how an athlete chose to quantify their change in overall training intensity.

Almost all of the elite CrossFit athletes surveyed had utilised a taper, and half of these athletes who had tapered stated that they always tapered for competition. Tapering was undertaken for similar reasons to other strength sports previously investigated ${ }^{13,19,20}$; such as achieving peak performance, to recover (physically and psychologically), and to reduce 
feelings of fatigue. As with these previously investigated strength sports, elite CrossFit athletes training changed prior to competition to become more specific to competition demands. Athletes in the current study described adapting their training to suit the different styles of competition they may encounter in the Open, Regionals or the Games. Such a step is logical as it ensures athletes are prepared for the specific demands likely to be encountered in competition.

Elite CrossFit athletes had generally experienced poor results from tapering when they tapered for too long or did not taper sufficiently. Similar trends have been reported for Powerlifters and Strongman competitors ${ }^{13,19}$. These studies emphasised the importance of utilising training diaries, or other means of recording training practices, so that athletes or their coaches who prescribe training are able to reflect upon and improve their tapering practices. This should include external measures of training load such as work performed, along with internal measures of training load such as session RPE ${ }^{25}$. Such a strategy is valuable, as it also allows for individualisation of tapering strategies. Sometimes issues outside of an athlete's control, such as injury and illness, had negatively influenced the taper. Yet even in these circumstances, reflection may be of value to determine if perhaps the pretaper training phase (i.e. too high a training load) contributed to the poor taper.

Few studies have investigated the tapering or competition day practices of elite athletes. It would be valuable to determine whether coaches recommend, and elite athletes follow, the recommended strategies across a range of sports. The current study was limited to elite CrossFit athletes, hence the results should be interpreted cautiously if applied to non-elite CrossFit athletes or to elite athletes from other sports. Future investigations into tapering 
practices within other sports with similar concurrent demands are recommended, such as combat and team sports. This would allow for specific applications in other sports, as well as provide valuable insights for CrossFit athletes and coaches. Given the current study used a survey in the English language only, this is a limitation in both the number of responses and potential depth of responses for those whom English is not their native tongue. Furthermore, the present study is limited in that it was only a descriptive study of what elite CrossFit athletes do, it would be beneficial to have elite athletes or their coaches quantify the effectiveness of their tapering strategies. Another influence on competition day performance are the specific practices of athletes on the day of competition. Understanding strategies used by CrossFit athletes to prepare on the day of competition, and the effectiveness of these, may assist athletes in preparing for similar sports with multiple events occurring within a single day or a few days.

This study has demonstrated that elite CrossFit athletes utilise a taper, and their tapering practices generally follow the previously recommended strategies of focusing on substantial volume reductions while maintaining or increasing training intensity. This information may be of value for other coaches and athletes engaged in sports with concurrent training and competition demands. However, as this is only a report of how elite athletes taper and not of the effectiveness of such strategies, the results should be interpreted accordingly. 


\section{Acknowledgements}

The authors would like to express their gratitude to the athletes who participated in the survey. Without your participation this research would not have been possible.

Declaration of Interest Statement

No potential conflict of interest was reported by the authors.

Word Count to this point (excl. title page):

4,093 


\section{References}

1. Eather N, Morgan PJ and Lubans DR. Improving health-related fitness in adolescents: The CrossFit Teens ${ }^{\mathrm{TM}}$ randomised controlled trial. Journal of Sports Sciences 2016; 34: 209-223.

2. CrossFit. 2018 Reebok CrossFit Games Season Schedule, https://games.crossfit.com/article/2018-reebok-crossfit-games-season-schedule (2017, accessed 26th June 2019).

3. Claudino JG, Gabbett TJ, Bourgeois F, et al. Crossfit overview: Systematic review and meta-analysis. Sports Medicine - Open 2018; 4: 11.

4. Coffey VG and Hawley JA. Concurrent exercise training: do opposites distract? The Journal of Physiology 2017; 595: 2883-2896.

5. Le Meur Y, Hausswirth C and Mujika I. Tapering for competition: A review. Science \& Sports 2012; 27: 77-87.

6. Wilson JM and Wilson GJ. A practical approach to the taper. Strength \& Conditioning Journal 2008; 30: 10-17.

7. Pritchard HJ, Barnes MJ, Stewart RJ, et al. Higher vs. lower intensity strength training taper: Effects on neuromuscular performance. International Journal of Sports Physiology and Performance 2019; 14: 458-463.

8. Papacosta E, Gleeson M and Nassis GP. Salivary hormones, IgA, and performance during intense training and tapering in judo athletes. The Journal of Strength \& Conditioning Research 2013; 27: 2569-2580.

9. Carazo-Vargas $P$ and Moncada-Jiménez J. Reducing training volume during tapering improves performance in Taekwondo athletes. Journal of Physical Education and Sport 2018; 18: 2221-2229.

10. Coutts AJ, Reaburn P, Piva TJ, et al. Changes in selected biochemical, muscular strength, power, and endurance measures during deliberate overreaching and tapering in rugby league players. International Journal of Sports Medicine 2007; 28: 116-124.

11. Fessi MS, Zarrouk N, Di Salvo V, et al. Effects of tapering on physical match activities in professional soccer players. Journal of Sports Sciences 2016; 34: 2189-2194.

12. Pritchard $\mathrm{H}$, Keogh J, Barnes $\mathrm{M}$, et al. Effects and mechanisms of tapering in maximizing muscular strength. Strength \& Conditioning Journal 2015; 37: 72-83.

13. Winwood PW, Dudson MK, Wilson D, et al. Tapering practices of strongman athletes. Journal of Strength \& Conditioning Research 2018; 32: 1181-1196.

14. Winwood PW, Pritchard HJ and Keogh JW. Tapering practices of strongman athletes: Test-retest reliability study. JMIR Research Protocols 2017; 6: e211.

15. Glassman G. A theoretical template for crossfit's programming. CrossFit Journal 2003; 6: 1-5.

16. Weisenthal BM, Beck CA, Maloney MD, et al. Injury rate and patterns among CrossFit athletes. Orthopaedic Journal of Sports Medicine 2014; 2: 2325967114531177.

17. Mujika I and Padilla S. Scientific bases for precompetition tapering strategies. Medicine and Science in Sports and Exercise 2003; 35: 1182-1187.

18. Mujika I. Intense training: The key to optimal performance before and during the taper. Scandinavian Journal of Medicine \& Science in Sports 2010; 20: 24-31.

19. Pritchard HJ, Tod DA, Barnes MJ, et al. Tapering practices of New Zealand's elite raw powerlifters. Journal of Strength \& Conditioning Research 2016; 30: 1796-1804.

20. Grgic J and Mikulic P. Tapering practices of Croatian open-class powerlifting champions. Journal of Strength \& Conditioning Research 2017; 31: 2371-2378. 
21. Bosquet L, Montpetit J, Arvisais D, et al. Effects of tapering on performance: A metaanalysis. Medicine \& Science in Sports \& Exercise 2007; 39: 1358-1365.

22. Weiss LW, Wood LE, Fry AC, et al. Strength/power augmentation subsequent to shortterm training abstinence. Journal of Strength \& Conditioning Research 2004; 18: 765-770. 23. Anderson T and Cattanach D. Effects of three different rest periods on expression of developed strength. Journal of Strength \& Conditioning Research 1993; 7: 185.

24. Spilsbury KL, Fudge BW, Ingham SA, et al. Tapering strategies in elite British endurance runners. European Journal of Sport Science 2015; 15: 367-373.

25. McGuigan M. Monitoring training and performance in athletes. $1^{\text {st }}$ ed. Champaign: Human Kinetics, 2017. 
Tables:

Table 1. Demographic \& training characteristics (mean $\pm \mathrm{SD}$ ) for elite CrossFit athletes

\begin{tabular}{|c|c|cc|}
\hline Age $(\mathrm{y})$ & $\begin{array}{c}\text { All Athletes } \\
(\mathrm{n}=72)\end{array}$ & $\begin{array}{c}\text { Female } \\
(\mathrm{n}=39)\end{array}$ & $\begin{array}{c}\text { Male } \\
(\mathrm{n}=33)\end{array}$ \\
\hline Height $(\mathrm{cm})$ & $26.5 \pm 3.6$ & $27.3 \pm 3.7$ & $25.7 \pm 3.5$ \\
\hline Body mass (kg) & $167.1 \pm 9.5$ & $161.2 \pm 26.6$ & $174.0 \pm 7.5^{*}$ \\
\hline General Training Experience (y) & $74.5 \pm 12.7$ & $63.9 \pm 11.5$ & $86.6 \pm 5.9 *$ \\
\hline CrossFit Training Experience (y) & $5.4 \pm 1.7$ & $5.5 \pm 1.9$ & $5.3 \pm 1.5$ \\
\hline Competitive CrossFit Experience (y) & $4.4 \pm 1.7$ & $4.6 \pm 1.7$ & $4.2 \pm 1.6$ \\
\hline Total Training Days (/wk) & $5.5 \pm 0.6$ & $5.6 \pm 0.6$ & $5.4 \pm 0.7$ \\
\hline Resistance Training Sessions (/wk) & $4.8 \pm 2.2$ & $4.3 \pm 1.2$ & $5.5 \pm 2.8$ \\
\hline Aerobic Training Sessions (/wk) & $4.1 \pm 2.3$ & $4.1 \pm 2.1$ & $4.2 \pm 2.6$ \\
\hline Anaerobic Training Sessions (/wk) & $4.3 \pm 2.2$ & $4.3 \pm 2.3$ & $4.3 \pm 2.1$ \\
\hline Training Session Duration (min) & $120.7 \pm 36.7$ & $120.1 \pm 35.5$ & $121.5 \pm 38.6$ \\
\hline
\end{tabular}

N.B. * denotes a significant difference between males and females $(P=\leq 0.001)$ 
Table 2. How training differs before various competitions $(n=63)$

\begin{tabular}{|c|c|c|}
\hline Higher Order Themes & Responses & Representative raw data \\
\hline \multicolumn{3}{|c|}{ Training Prior to the Open } \\
\hline $\begin{array}{l}\text { Higher-intensity, shorter } \\
\text { duration, metabolic } \\
\text { conditioning is a focus }\end{array}$ & 18 & $\begin{array}{l}\text { "Prior to the open, the training focuses on } \\
\text { more intense, shorter duration workouts" }\end{array}$ \\
\hline Aerobic conditioning is a focus & 16 & $\begin{array}{c}\text { "Usually before the open the training is more } \\
\text { cardio and metcon" }\end{array}$ \\
\hline Training loads are lighter & 7 & $\begin{array}{l}\text { "Prior to the Open, focus on lighter loads and } \\
\text { common movements in crossfit style metcons" }\end{array}$ \\
\hline \multicolumn{3}{|c|}{ Training Prior to the Regionals } \\
\hline $\begin{array}{c}\text { Heavier load strength work is } \\
\text { utilised }\end{array}$ & 19 & $\begin{array}{c}\text { "Before Regionals --> heavier loads, more } \\
\text { lifting/strength" }\end{array}$ \\
\hline $\begin{array}{l}\text { Higher training volumes are } \\
\text { utilised }\end{array}$ & 16 & $\begin{array}{l}\text { "Regionals training was higher volume to prep } \\
\text { for back to back workouts" }\end{array}$ \\
\hline $\begin{array}{l}\text { Competition specific event } \\
\text { practice occurs }\end{array}$ & 12 & $\begin{array}{l}\text { "Regionals we also got to practice for the } \\
\text { specific events announced ahead of time" }\end{array}$ \\
\hline $\begin{array}{l}\text { Practicing high skill } \\
\text { movements is a focus }\end{array}$ & 9 & "Training for regionals is higher skill" \\
\hline \multicolumn{3}{|c|}{ Training Prior to the Games } \\
\hline $\begin{array}{l}\text { Training volume is a main } \\
\text { priority }\end{array}$ & 6 & "The games is mainly volume" \\
\hline $\begin{array}{l}\text { Training for unknown } \\
\text { movements }\end{array}$ & 5 & $\begin{array}{c}\text { "Games you can expect anything. As well as } \\
\text { weird movements" }\end{array}$ \\
\hline
\end{tabular}

N.B. Some athletes provided information that was representative of more than one theme and thus contributed to more than one theme. Metcon = metabolic conditioning style workouts. 
Table 3. Coaching and taper characteristics of elite CrossFit athletes

\begin{tabular}{|c|c|cc|}
\hline & All Athletes & Female & Male \\
\hline Coaching & $\mathrm{n}=72$ & $\mathrm{n}=39$ & $\mathrm{n}=33$ \\
\cline { 2 - 4 } Have a Coach & $54(75.0 \%)$ & $34(87.2 \%)$ & $20(60.6 \%)$ \\
Self-Coached & $13(18.1 \%)$ & $3(7.7 \%)$ & $10(30.3 \%)$ \\
Other & $5(6.9 \%)$ & $2(5.1 \%)$ & $3(9.1 \%)$ \\
\hline Taper & & $\left.7.143^{(\mathrm{a})}\right)^{(\mathrm{b})} \mathrm{p}=0.028^{(\mathrm{c})}$ \\
\hline Yes & $71(98.6 \%)$ & $38(97.4 \%)$ & $33(100 \%)$ \\
No & $1(1.4 \%)$ & $1(2.6 \%)$ & $0(0.0 \%)$ \\
\hline Taper Type & $\mathrm{n}=66$ & $\mathrm{n}=34$ & $\mathrm{n}=32$ \\
\cline { 2 - 4 } Step Taper & $28(42.4 \%)$ & $10(29.4 \%)$ & $18(56.3 \%)$ \\
Linear Taper & $20(30.3 \%)$ & $13(38.2 \%)$ & $7(21.9 \%)$ \\
Exponential Taper & $10(15.2 \%)$ & $5(14.7 \%)$ & $5(15.6 \%)$ \\
Other & $8(12.1 \%)$ & $6(17.6 \%)$ & $2(6.3 \%)$ \\
\hline Always Taper & & \multicolumn{2}{|c|}{12 (38.7\%) } \\
Yes & $33(50.0 \%)$ & $21(60.0 \%)$ & $19(61.3 \%)$ \\
\hline No & $33(50.0 \%)$ & $14(40.0 \%)$ & \\
\hline
\end{tabular}

N.B. Data presented as occurrences followed by, in parentheses, percentage. (a) Chi square value (b) Degrees of freedom (c) $p$ value. Participant number discrepancies appear for "taper type" and "always taper" as data was not always reported by CrossFit athletes. 
Table 4. Why tapering is used prior to important competitions $(n=66)$

\begin{tabular}{|c|c|c|}
\hline Higher Order Themes & Responses & Representative raw data \\
\hline Physical recovery & 26 & $\begin{array}{c}\text { "So that my body is as recovered as } \\
\text { possible" }\end{array}$ \\
\hline Peak performance & 21 & $\begin{array}{c}\text { "To be able to perform fully at } 100 \% \\
\text { capacity" }\end{array}$ \\
\hline Psychological readiness & 21 & $\begin{array}{c}\text { "To mentally prepare for } \\
\text { competition. I want to feel fresh } \\
\text { during competition" }\end{array}$ \\
\hline Reduce soreness / fatigue & 13 & $\begin{array}{c}\text { "To flush out soreness and to } \\
\text { diminish fatigue" }\end{array}$ \\
\hline Rest & 8 & $\begin{array}{c}\text { "It is very important to give your } \\
\text { body that rest before a big } \\
\text { competition" }\end{array}$ \\
\hline Psychological recovery & 8 & $\begin{array}{l}\text { "To ensure my body and mind is } \\
\text { fully recovered" }\end{array}$ \\
\hline
\end{tabular}

N.B. Some athletes provided information that was representative of more than one theme and thus contributed to more than one theme. 
Table 5. Details of tapering practices of elite CrossFit athletes

\begin{tabular}{|c|c|cc|}
\hline & $\begin{array}{c}\text { All Athletes } \\
(\mathrm{n}=50)\end{array}$ & $\begin{array}{c}\text { Female } \\
(\mathrm{n}=25)\end{array}$ & $\begin{array}{c}\text { Male } \\
(\mathrm{n}=25)\end{array}$ \\
\hline Change in Training Intensity & & & \\
Increases & $10(20.0 \%)$ & $5(20.0 \%)$ & $5(20 \%)$ \\
Stays the Same & $16(32.0 \%)$ & $5(20.0 \%)$ & $11(44.0 \%)$ \\
Decreases & $24(48.0 \%)$ & $15(60.0 \%)$ & $9(36.0 \%)$ \\
\hline $\begin{array}{c}\text { Change in Training } \\
\text { Frequency } \\
\text { Increases }\end{array}$ & $0(0.0 \%)$ & $0(0.0 \%)$ & $0(0.0 \%)$ \\
Stays the Same & $25(50.0 \%)$ & $12(48.0 \%)$ & $13(52.0 \%)$ \\
Decreases & $25(50.0 \%)$ & $13(52.0 \%)$ & $12(48.0 \%)$ \\
\hline Change in Training Duration & & & \\
Increases & $0(0.0 \%)$ & $0(0.0 \%)$ & $0(0.0 \%)$ \\
Stays the Same & $5(10.0 \%)$ & $3(12.0 \%)$ & $2(8.0 \%)$ \\
Decreases & $45(90.0 \%)$ & $22(88.0 \%)$ & $23(92.0 \%)$ \\
\hline Change in Training Volume & & & $40.4 \pm 18.5 \%$ \\
Reported Volume Change & $41.2 \pm 15.5 \%$ & $42.0 \pm 13.3 \%$ & \\
\hline
\end{tabular}

N.B. Data presented as occurrences followed by, in parentheses, percentage. 
Table 6. When tapering hasn't worked and why $(n=20)$

\begin{tabular}{|c|c|c|}
\hline Higher Order Themes & Responses & Representative raw data \\
\hline Tapered for too long & 9 & $\begin{array}{c}\text { "I tapered too early and went into } \\
\text { competition feeling tight and my lifts were a } \\
\text { little bit off" }\end{array}$ \\
\hline Insufficient tapering & 5 & $\begin{array}{c}\text { "Because I love training sometimes I get } \\
\text { carried away in workouts too close to the } \\
\text { comp" }\end{array}$ \\
\hline Miscellaneous & 7 & $\begin{array}{c}\text { "Misplanned events - nutritional mistakes" } \\
\text { "Usually because I was overtrained weeks } \\
\text { prior" } \\
\text { "It has been other things that went wrong } \\
\text { (injury, menstruation timing, external } \\
\text { factors...)" }\end{array}$ \\
\hline
\end{tabular}

N.B. Some athletes provided information that was representative of more than one theme and thus contributed to more than one theme. Twelve athlete's responses indicated tapering had always been successful, thus their responses were excluded from this question. 
Table 7. Resistance training movements loads used, and when last performed (mean $\pm S D$ ), prior to competition

\begin{tabular}{|c|c|c|c|c|}
\hline \multirow{2}{*}{} & \multicolumn{2}{|c|}{ Weightlifting Movements } & \multicolumn{2}{c|}{ Powerlifting Movements } \\
\cline { 2 - 5 } & $\begin{array}{c}\text { Snatch } \\
(\mathrm{n}=38)\end{array}$ & $\begin{array}{c}\text { Clean \& Jerk } \\
(\mathrm{n}=28)\end{array}$ & $\begin{array}{c}\text { Back Squat } \\
(\mathrm{n}=28)\end{array}$ & $\begin{array}{c}\text { Deadlift } \\
(\mathrm{n}=17)\end{array}$ \\
\hline When last performed (days) & $2.6 \pm 1.2$ & $3.6 \pm 1.3^{*} .015$ & $3.8 \pm 1.6^{*} .006$ & $5.3 \pm 2.9^{*} .008$ \\
\hline Loads used (\% 1RM) & $74.7 \pm 12.1$ & $71.4 \pm 10.3$ & $73.6 \pm 10.4$ & $70.0 \pm 13.7$ \\
\hline
\end{tabular}

*Significantly different to snatch movement

\#Consist of the clean $(n=10)$ and the clean and jerk $(n=18)$

N.B. Other movements had two or fewer responses, so were not included above. 
Figures

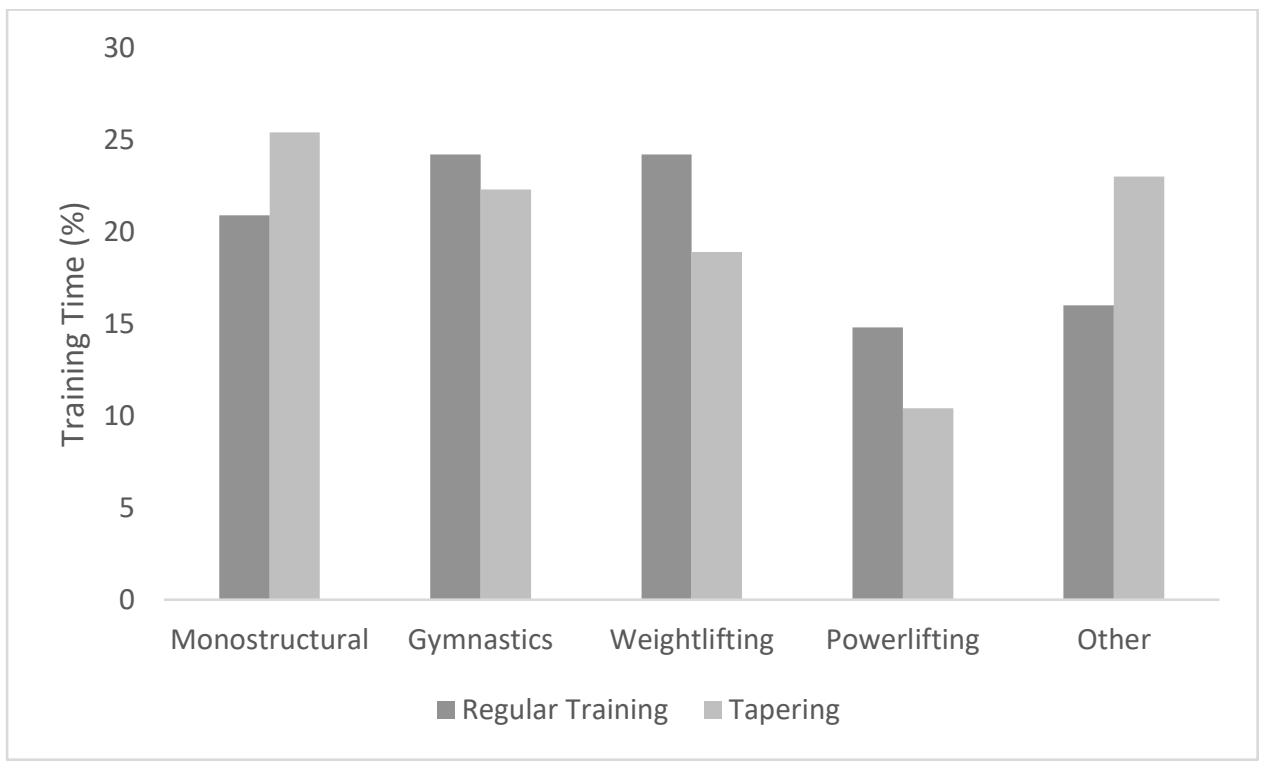

Figure 1. Training time by modality (as percentage of total training) 


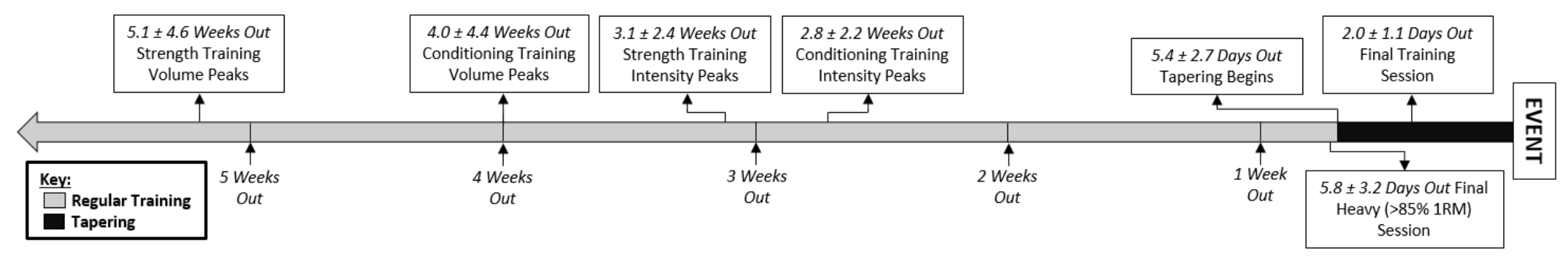

Figure 2. Tapering events timeline 


\section{Figure Captions}

Figure 1 . Training time by modality (as percentage of total training)

Figure 2. Tapering events timeline 